\title{
OS SUPRIDORES, DE JOSÉ FALERO: A PERIFERIA DO RIO GRANDE DO SUL EM FOCO
}

\author{
OS SUPRIDORES, BY JOSÉ FALERO: THE \\ BRAZILIAN SOUTHERN'S PERIPHERY IN \\ FOCUS
}

Lisiani Coelho*

Alfeu Sparemberger $*$

Resumo: A presente resenha objetiva a apresentação do romance Os supridores, do escritor gaúcho José Falero, publicado pela Editora Todavia em 2020. Nesta narrativa, ambientada em um cenário periférico, a população marginalizada assume o comando das ações, mostrando-se consciente em relação ao desequilíbrio das classes sociais no Brasil. Entre aceitar uma vida cheia de privações ou entrar no submundo do tráfico, os personagens centrais da trama escolhem a segunda opção, protagonizando um enredo que mistura a filosofia do tráfico com a filosofia marxista.

Palavras-chave: José Falero, periferia, Marxismo.

Aвstract: The present review aims the presentation of the novel Os supridores, written by José Falero and published by Editora Todavia in 2020. In the narrative, set in a peripheral scenario, the marginalized population takes the lead of the actions, showing awareness related to the imbalance of social classes in Brazil. Between accepting a life full of deprivation or entering the underworld of drug trafficking, the characters choose the second option, starring a plot which mixes the philosophies of trafficking and Marxism.

KEYwords: José Falero, periphery, Marxism.

\footnotetext{
"Mestranda em Letras (Literatura, cultura e tradução) pela Universidade Federal de Pelotas (UFPel). E-mail: lisi.mae@ hotmail.com.

"* Doutor em Letras pela Universidade de São Paulo (USP) e docente da área de Literatura nos programas de Graduação e Pós-Graduação pela Universidade Federal de Pelotas (UFPel). E-mail: berger9889@gmail.com.
} 
Os supridores é o romance de estreia do porto-alegrense José Carlos da Silva Junior (1987) ou José Falero - como é conhecido no mundo literário -, nascido e criado na Lomba do Pinheiro, bairro periférico da capital gaúcha. O livro foi publicado no final do turbulento ano de 2020 pela Editora Todavia. Esta não é, contudo, a estreia literária do autor, que já divulgava seus textos no meio virtual desde 2018 e, no ano seguinte, lançou o bem-sucedido livro de contos Vila Sapo (Editora Venas Abiertas), o qual o colocou no mapa das grandes editoras. Atualmente, o autor mantém uma coluna semanal na revista Parêntese, publicação digital gaúcha. Além disso, a afinidade com o meio artístico não se resume à literatura, pois José Falero é também desenhista e músico, além de desenvolvedor de software.

O autor, assim como um considerável número de novos escritores da atualidade, emerge de um lugar não tradicional de escrita, barrado pelo poder da hegemonia social e cultural que define os sistemas literários. Tanto a leitura quanto a escrita, dentro de espaços sociais marginalizados, adquirem um valor que excede o aspecto artístico e se apresenta como ferramenta de resistência, instaurando uma verdadeira "disputa” por território. O nacional comporta uma pluralidade de vozes que, ao se fazerem ouvidas/lidas, revelam que a escrita é um campo de batalha complexo e capaz de operar mudanças significativas; esses textos não são produzidos ao acaso, fazem parte de um projeto de emancipação identitária e artística bastante coerente.

Por intermédio de autores como Falero, a ficção periférica passa a ocupar um espaço considerável dentro do sistema literário nacional, trazendo novas vozes que tratam destes temas necessários por meio de uma visão privilegiada, tendo em vista que estes escritores falam de dentro de suas comunidades de origem. A literatura periférica ou marginal - a denominação varia de acordo com a região, autor e proposta literária - teve, por um longo período de tempo, a cidade de São Paulo como seu principal polo de produção e, atualmente, começa a expandir esse reconhecimento para outras partes do país; agora, então, é a vez de o Rio Grande do Sul apresentar seu mais novo representante do gênero.

Falero ocupou, por muitos anos, espaços de trabalho designados para a população de origem periférica: servente de pedreiro, auxiliar de cozinha, supridor de supermercado; isto, no entanto, não o impediu de ter na literatura um grande suporte de vida. Parte desta perspectiva, que eleva o valor do livro ao tratar do cotidiano sofrido de muitos brasileiros, fica evidente em suas personagens e na trama de Os supridores.

O livro narra a história de Pedro e Marques, dois jovens da classe baixa que trabalham como supridores - o mesmo que abastecedores - em uma das filiais da fictícia rede de supermercados Fênix, na região central de Porto Alegre. Esta atividade laboral, como supracitado no perfil do escritor, foi exercida por Falero em um momento anterior de sua vida. Não se trata, neste caso, de reprisar uma experiência vivida, de apresentar um testemunho - algo muitas vezes associado, genericamente, à literatura periférica -, mas de aplicar um cenário e um contexto conhecidos a uma trama que dá conta da difícil situação de vida de grande parte da população brasileira. O significado da palavra supridor, que dá título à obra, é modificado 
para incluir um empreendimento diferente e bem mais lucrativo (apesar de ilícito) que o de abastecer gôndolas e prateleiras de supermercado.

Antes de dar início às ações dos dois companheiros, Falero reproduz uma geografia da pobreza, descrevendo, com riqueza de detalhes, o estabelecimento do bairro que abriga Pedro e que impulsiona seus ideais de negócios.

[...] afastada do Centro, fora do alcance dos tentáculos do poder público, abandonada à própria sorte, assim tinha construído em torno de si uma assustadora fama de terra sem lei, onde nem as mais abomináveis selvagerias eram motivo de surpresa [...]. Dúzias de vilas compunham o bairro, todas crescendo e crescendo sem qualquer planejamento às margens da estrada, todas derramando-se desordenadamente por encostas íngremes, todas fazendo fronteira com algum matagal (FALERO, 2020, p. 18).

Esta caracterização aponta a condição precária em que vivem muitos dos moradores da capital gaúcha, motivando no jovem a busca por uma melhor qualidade de vida que não mede os custos envolvidos:

Só o que eu faço é suar e suar para me manter respirando, e mais nada. Uma puta duma usina trabalhando a todo o vapor só para acender uma bosta duma lâmpada! É, eu preciso ficar rico, custe o que custar. Preciso dar um jeito de experimentar as coisa que faz a existência valer a pena, e não vai ser trabalhando que eu vou conseguir isso (FALERO, 2020, p. 24).

Cansado de sua posição dentro do mercado de trabalho e sem perspectivas de subir de cargo, Pedro visualiza uma brecha em um outro ramo de negócios: o do tráfico de drogas. O protagonista de Falero percebe que em seu bairro, e em muitos outros da capital gaúcha, não há uma extensiva venda de maconha, pois os traficantes preferem vender cocaína e crack, drogas mais caras e que, por consequência, dão maior retorno financeiro. Depois de muitas discussões entre os amigos, o negócio começa a funcionar e com resultados mais satisfatórios que os esperados inicialmente.

$\mathrm{O}$ ato de suprir, diariamente exercido pelos dois amigos, continua sendo sua fonte de renda, porém, se antes suprir significava trabalhar horas a fio em um calor escaldante, recebendo um salário que mal cobria as necessidades básicas deles e de seus familiares - Pedro ajudando sua mãe, empregada doméstica, e Marques sustentando sua família, esposa grávida e um filho pequeno-, agora passou a significar o fornecimento de maconha nos bairros em que circulam. O negócio tornou-se tão bem sucedido que foi necessário contratar novos funcionários para dar conta do serviço e ampliar a renda ganha pelo grupo. Angélica, a esposa grávida de Marques, Roberto, esposo da prima de Pedro e Lucas, ex-empacotador do supermercado Fênix, completam o grupo. 
Além da função de supridor, Falero "empresta” ao seu protagonista Pedro, grande articulador da narrativa, a afinidade com a leitura, ou seja, a possibilidade de um novo mundo que começa com a expansão de pensamentos estimulada pelos livros. Pedro, apesar da rotina extenuante, sempre encontra tempo para ler, utilizando os livros, incialmente, como uma válvula de escape, algo que tira seu foco da miséria em que vive: "Eu, na real, nem posso dizer que eu vivo: eu sobrevivo" (FALERO, 2020, p. 24). Neste meio tempo, o livro lhe trouxe a filosofia marxista, algo que ele passa a usar como parâmetro para a construção de uma nova identidade. Ler, a invés de trazer conforto e apaziguar sentimentos pesados, deixou a personagem ainda mais desconfortável com a vida que levava; o jovem passa a questionar as desigualdades sociais e a incessante exploração da mão de obra da classe baixa. Como ressalta DaMatta (2011, p. 20), “[...] a literatura, como prática social, ajuda a construir representações que extrapolam o texto e o próprio campo literário", atuando na conquista da emancipação do leitor. Este incômodo, proporcionado pelas leituras de Pedro, foi, aos poucos, sendo transferido para o seu novo colega de trabalho, Marques, que curiosamente traz no nome semelhança com o filósofo alemão Karl Marx, autor fonte da inspiração de Pedro.

- É, parece que tu tá certo, como sempre. Mas vem cá: se eu sou teu discípulo, tu é discípulo de quem? Quem é o teu mestre? Fala aí.

- Bah, mano. Eu bebo num monte de fonte. Eu tenho uma pá de mestre. [...] Sei lá, eu acho que o cara que mais influenciou o meu pensamento foi um filósofo alemão. O nome dele era Marx [...].

- O nome do cara era Marques, que nem o meu?

- Não. Era Marx, com xis (FALERO, 2020, p. 58-59).

Em determinado momento da narrativa, os diálogos entre Pedro e Marques adquirem caráter didático, quando o primeiro "educa” o segundo na complexa teoria marxista, utilizando exemplos do cotidiano dos dois e estimulando em Marques o desejo de crescer:

- [...] Olha, eu tô tentando te explicar é que existe um limite até onde a gente pode fazer as coisa sozinho, Marques. Existe um limite. E esse limite, que varia de pessoa pra pessoa, esse limite é que devia definir o melhor padrão de vida possível pra cada pessoa. [...] Se o nosso trabalho é fazer camisa, por exemplo, talvez eu consiga fazer umas cinco camisa por dia, mas pode ser que tu seja capaz de fazer seis, não é verdade? E se tu faz mais camisa do que eu, o teu padrão de vida tem que ser melhor que o meu.

- Tá, e não é isso que acontece?

- O quê? Meu Deus, em que mundo tu vive? Claro que não é isso que acontece! (FALERO, 2020, p. 46-47). 
Alfredo Bosi, em seu ensaio "A escrita e os excluídos" (2002), analisa a presença do excluído na literatura, discutindo, dentre outros aspectos, a relação destes sujeitos com a cultura letrada. Ao trabalhar voluntariamente com um grupo de operários da periferia de São Paulo na década de 70 do século 20 , o autor chega à seguinte conclusão:

[...] tomei consciência de que os excluídos do "milagre econômico" [...] ansiavam, em primeiro lugar, pelo acesso ao conhecimento. E mediante o conhecimento, ter vez e voz em um mundo que se fecha para os que não conseguiram transpor o limiar da escrita (BOSI, 2002, p. 263).

Considera-se, aqui, a mesma "fome" de conhecimento e crescimento observada em Pedro e estendida a Marques, que, apesar de não ser um leitor, se alimenta da leitura do amigo e passa a refletir sobre as condições de exploração em que vivem.

O livro é narrado em terceira pessoa, por um narrador onisciente, com um texto repleto de extensos diálogos, que variam entre momentos tensos e engraçados vividos pelos protagonistas e seus comparsas. A trama é dividida em 22 capítulos e traz, em resumo, três diferentes momentos: o período inicial, no qual o cenário é montado e os dois protagonistas encontram-se e começam a dividir aspectos importantes de suas vidas, até o momento em que Pedro consegue convencer Marques a iniciar seu negócio paralelo de venda de maconha; na sequência, é narrada a trajetória dos amigos em seu novo negócio, com erros, acertos e a adição de novos "supridores" ao grupo inicial; a parte final representa o momento em que tudo começa a desmoronar e o sucesso do empreendimento cai por terra. A violência e o ódio, até então distantes da narrativa - algo bastante incomum às narrativas periféricas, normalmente marcadas por manifestação excessiva de violência -, passam a ocupar o centro da trama, ao que Bernardo Carvalho, em apreciação contida na contracapa do livro, indica lembrar as obras cinematográficas do diretor norte-americano Quentin Tarantino.

De fato, os últimos capítulos do livro, que até o momento trazia uma narrativa de desenvolvimento lento e sem grandes complicações, passam a exigir deles e do leitor um ritmo frenético de raciocínio e ação, dotado de reviravoltas e fortemente manchado por sangue. No auge do empreendimento, quando o grupo já possuía dinheiro suficiente para sair do tráfico, além da conquista de negócios lícitos paralelos, Lucas - o integrante mais jovem do grupo e também o menos interessado em abandonar o esquema lucrativo - é removido, de forma violenta, de sua posição no bairro onde vende a droga. Um outro grupo lá se estabelece, tentando acabar com sua vida; o rapaz, no entanto, consegue fugir, e, revoltados, os traficantes executam sua mãe. Lucas, auxiliado pelos comparsas, busca vingança pela perda materna, ato que motiva o banho de sangue que encerra as atividades do grupo.

A calmaria advinda do sucesso absoluto dos protagonistas trazia em si um foco de tensão, pois o leitor experiente é capaz de inferir que as coisas estavam perfeitas demais, e, à medida que o livro vai se encaminhando para o final e a situação continua a mesma, faz com 
que a leitura avance com mais velocidade, tendo em vista a necessidade de visualizar uma reviravolta, que, neste caso, veio e não decepcionou seu público. O castelo de areia, estrategicamente construído por Pedro, rapidamente desmorona e leva consigo o grande mentor do negócio. Enquanto Lucas encontra seu fim no cano de uma arma, os outros comparsas de Pedro saem ilesos e com uma nova perspectiva de vida - tanto Marques e Angélica quanto Roberto, têm seus próprios negócios bem-sucedidos, não precisando retornar ao mundo do tráfico e nem cumprir pena. Pedro, que decide não entregar seus amigos, passa a ocupar uma cela de cadeia e utiliza, mais uma vez, a literatura como meio de sobrevivência, passando a escrever, o que, ao final, descobre-se ser o próprio livro Os supridores: "E se tu, leitor, estiveres lendo isto, très bien. É porque Pedro conseguiu escrever tudo o que desejava” (FALERO, 2020, p. 301). Falero utiliza o inteligente recurso narrativo de contar uma história que, desde o início, sabe-se que ocorreu anos atrás, mas sem entregar, em momento algum, que o próprio narrador é o protagonista da história. Esta perspectiva cria uma reviravolta que satisfaz o leitor, além de plantar uma dúvida sobre a veracidade dos fatos narrados.

A linguagem escolhida oscila entre a variante culta e a coloquial da língua portuguesa. A voz do narrador, por ser construída em terceira pessoa, é totalmente escrita em norma culta, convertida, no entanto, em linguagem coloquial e gírias da periferia gaúcha quando os diálogos assumem a cena, em uma possível tentativa de produzir "veracidade" nas interações entre as personagens. Todavia, esse aspecto pode, e deve, ser amplamente discutido nas produções literárias contemporâneas: o emprego do "desvio" da norma culta na fala de personagens periféricos é observado na escrita de muitos outros autores do gênero, como por exemplo, Geovani Martins, que o utiliza alternadamente em seus contos. Por tratar-se, aqui, de textos literários, e não da realidade em si, talvez essa alternância não seja algo que deva ser naturalizado, por conter em sua essência um aspecto que possa ser lido como um fortalecimento do preconceito linguístico, mesmo que essa não seja a intenção dos autores que a utilizam. Essa prática pode estar vinculada, além da questão da "autenticidade" dos diálogos, a um esforço de marcação de espaços dentro da sociedade, algo há muito tempo problematizado pela Sociolinguística quando em análise dos diferentes grupos sociais e suas pautas. Quando a alternância parte de um autor que não utiliza/vivencia esta forma coloquial em seu meio, a questão torna-se mais problemática ainda, justificando o argumento da manutenção do preconceito linguístico. Enfim, esse ponto precisa ser problematizado com a devida atenção, não sendo esta a proposta da resenha; a intenção é apenas a de somar informações ao debate do uso da linguagem.

Falero não tenta construir um texto moralizante, indicando que o crime não compensa; pelo contrário, ele transforma em literatura uma das possibilidades de vida da população excluída, apontando como, muitas vezes, o crime entra na vida dos cidadãos e como ele é perpetuado dentro da sociedade. O romance mostra os mecanismos do tráfico de drogas e a violência - sem, no entanto, apoiar-se nele para construir a narrativa -, mas humaniza os 
responsáveis, dando conta de um mecanismo social raramente explicitado com tantos detalhes na literatura e que apresenta um grande potencial de exploração artística.

Se a leitura fez Pedro desenvolver habilidades para vencer sua fome e tantas outras adversidades, ler a trajetória desta personagem faz refletir sobre aspectos da sociedade que, na maioria das vezes, escolhemos não ver, desviando o olhar e seguindo em frente. A boa literatura é incômoda e, neste caso, é possível afirmar que Falero foi incômodo. Ele produziu um romance que se empenha em discutir relações de trabalho e o que essas relações refletem dentro de um contexto globalizado, que estimula o consumo desenfreado e não permite o acesso de todos a esses bens. Este claro desequilíbrio é capaz de gerar consequências desastrosas e, na maioria das vezes, irreparáveis.

Definitivamente, Falero merece ser lido. Depois de seu interessante, porém breve, livro de contos, que já lançava as bases para a escrita do romance de 300 páginas, o autor surpreende com sua intensa e reflexiva narrativa, que oferece espaço amplo para a formulação de novos romances e contos dentro deste universo com potencial de expansão. O prefácio de Vila Sapo, escrito por Evanilton Gonçalves, já demonstrava o tom do que parece vir a se estabelecer nas tramas de Falero, pois confirma-se, com ainda mais fôlego, em Os supridores:

Com tramas absurdamente sinceras e mudanças vertiginosas nas narrativas, Falero nos leva a pensar na instabilidade da vida. Afinal, estar bem é a grande meta de todos, mas as formas de alcançar esse objetivo é que variam, eis o mote para os conflitos que se desenrolam de forma tensa, mas divertida (GONÇALVES, 2019, p. 10).

Em um mundo ideal, a periferia gaúcha deveria ler Os supridores, uma vez que é sua história e suas ruas que configuram a inspiração de Falero. O próprio autor manifesta, em entrevista à Renata Moniz, da Revista Trip, seu desejo de ver a literatura circulando por todos os ambientes sociais: "Eu penso que a gente tem que arrancar a literatura do altar burguês em que ela foi metida. Eu acredito que a literatura deve pertencer ao povo" (FALERO, Trip, 2021). Infelizmente, o custo do livro torna esta possibilidade inviável para grande parte da população. Sendo assim, somente quem tem um maior poder aquisitivo vai ser capaz de acessar esta obra, que soma em qualidade ao movimento dos escritores periféricos nacionais. Talvez, futuramente, edições econômicas deste e de outros bons livros de escritores periféricos componham, também, as bibliotecas de escolas públicas, ampliando a possibilidade de leitura e discussão de um gênero que veio para ficar e que descreve tão bem as desigualdades vivenciadas em países de terceiro mundo. 


\section{REFERÊNCIAS}

BOSI, Alfredo. A escrita e os excluídos. In: BOSI, Alfredo. Literatura e resistência. São Paulo: Companhia das Letras, 2002. p. 257-269.

DAMATA, Anderson Luís Nunes. Representações e responsabilidade na narrativa brasileira contemporânea. In: DELCASTAGNÈ, Regina; THOMAZ, Paulo C. (org.). Pelas margens: representação na narrativa brasileira contemporânea. São Paulo: Editora Horizonte, 2011. p. 15-39.

FALERO, José. Os supridores. São Paulo: Todavia, 2020.

MONIZ, Renata. José Falero: a literatura deve pertencer ao povo. Revista Trip. São Paulo, fev. 2021. Disponível em: https://revistatrip.uol.com.br/trip/jose-falero-a-literatura-devepertencer-ao-povo. Acesso em: 5 mar. 2021.

GONÇALVES, Evanilton. Prefácio. In: FALERO, José. Vila Sapo. Porto Alegre: Venas Abiertas, 2019. p.7-14.

Recebido para publicação em: 26 abr. 2021. Aceito para publicação em: 11 out. 2021. 